\title{
Temperature variability and trends in the UT-LS over a subtropical site: Reunion $\left(20.8^{\circ} \mathrm{S}, 55.5^{\circ} \mathrm{E}\right)$
}

\author{
N. Bègue ${ }^{1}$, H. Bencherif ${ }^{1}$, V. Sivakumar ${ }^{2,3}$, G. Kirgis ${ }^{1}$, N. Mze ${ }^{1}$, and J. Leclair de Bellevue ${ }^{1}$ \\ ${ }^{1}$ Laboratoire de l'Atmosphère et des Cyclones, UMR 8105 CNRS, Université de la Réunion, Reunion Island, France \\ ${ }^{2}$ National Laser Centre (NLC), Council for Scientific and Industrial Research, Pretoria, South Africa \\ ${ }^{3}$ Department of Geography, Geo-informatics and Meteorology, University of Pretoria, Pretoria, South Africa
}

Received: 16 March 2010 - Published in Atmos. Chem. Phys. Discuss.: 16 April 2010

Revised: 17 August 2010 - Accepted: 3 September 2010 - Published: 13 September 2010

\begin{abstract}
This paper mainly focuses on the trends and variability of the UT-LS temperature using radiosonde observations carried out over 16 years (January 1993 to December 2008) from a southern subtropical site, Reunion $\left(20.8^{\circ} \mathrm{S}\right.$, $55.5^{\circ} \mathrm{E}$ ), using a linear-regression fitting model. Two kinds of tropopause definitions, namely, cold point tropopause (CPT) and lapse rate tropopause (LRT) are used. In order to characterize and quantify the relationship between regional oceanic forcing and temperature at UT-LS, we took into account the Indian Ocean Dipole (IOD) for the estimation of temperature trends. Results show that the main component is the Annual Cycle (AC), particularly at tropopause (CPT, LRT) and in the lower stratosphere (LS) where more than $26.0 \pm 2.4 \%$ of temperature variability can be explained by AC. The influence of IOD on the variability of the temperature is at highest ratio at CPT and LS, with respectively $12.3 \pm 7.3 \%$ and $13.1 \pm 5.9 \%$. The correlations between IOD and temperature anomalies at UT-LS are barely significant, which are found to be in close agreement with the results obtained by Rosenlof et al. (2008) over the western tropical Pacific Ocean. The temperature trend in the LS reveals a cooling of about $-0.90 \pm 0.40 \mathrm{~K}$ per decade. The cooling trend at LS is found to be in close agreement with the others studies. Trend estimates in the LS suggest that IOD forcing contributes to increasing cooling by about $0.16 \pm 0.05 \mathrm{~K}$ per decade. Past works have shown that the additional carbon dioxide increase has a minor effect in the LS, and suggested that other effects than ozone and carbon dioxide changes have to be considered, in order to explain the observed temperature changes in the LS. From this study, we can suggest that the SST changes can be considered also, in addition to
\end{abstract}

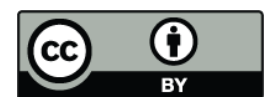

Correspondence to: N. Bègue (nelson.begue@univ-reunion.fr) effects due to ozone and carbon dioxide changes, in order to explain the observed temperature changes in the LS. As a consequence, our results support the assumption that the Indian Ocean may have a slight impact on temperature variability and on temperature change in the LS over Reunion.

\section{Introduction}

Troposphere-lower stratosphere temperature in the Earth's atmosphere plays an important role in radiation budget and understanding of various chemical elements (Rosenlof et al., 2001; Bethan et al., 1996; Pan et al., 2004). The main purpose of studying the troposphere and lower stratosphere temperature is a better understanding of the exchange of the trace elements between the troposphere and the stratosphere across the tropopause. Indeed, the tropopause marks the transition between the troposphere and the stratosphere and it plays an important role in Stratosphere-Troposphere Exchange (STE) and wave propagation between the two regions (Holton et al., 1995; Baray et al, 1997; Sorensen and Nielsen, 2000).

In fact, studies on tropopause characteristics are further expected to provide climatology, to investigate variability and anomalies of thermal structures and tracer distributions, notably ozone and water vapour, as well as exchange processes that contribute to redistribution of these compounds on both vertical and horizontal scales. Since air enters the stratosphere mainly through the tropical tropopause, the latter therefore plays an important role in the water vapour budget (as well as other trace compounds) in the stratosphere (Randel et al., 2000). Furthermore, it is well established that the seasonal cycle of water vapour entering the stratosphere is dominated by the seasonal temperature cycle near the tropopause (Mote et al., 1996). At the tropical tropopause

Published by Copernicus Publications on behalf of the European Geosciences Union. 
layer, temperature is a parameter controlling the input of water vapour from the troposphere and the dynamic properties of the region (Rosenlof et al., 2008). Inter-annual variation in tropopause temperatures have been linked to the quasibiennial oscillation, El Niño and episodic volcanic eruptions (Reid et Gage, 1985; Randel et al., 2000, 2004; Randel et Seidel, 2006). More recently, the presence of water vapour in the lower stratosphere and resulting changes in the ozone concentration/variability in the tropical tropopause have been highlighted by Randel et al. (2006). Moreover, when studying Sea Surface Temperature (SST) anomalies in the western tropical Pacific Ocean, Rosensolf et al. (2008) noted a significant anti-correlation between the SST and the temperature anomalies of the tropical stratosphere, and concluded that the increased cooling may be an indication of tropical convection strengthening.

A series of extensive trend analyses based on long-term records have shown a non-significant warming in the upper troposphere and a significant cooling in the lower stratosphere $(\sim 1 \mathrm{~K} / \mathrm{dec})$, with a cooling $(\sim 0.5 \mathrm{~K} / \mathrm{dec})$ at the tropopause (Ramaswamy et al., 2001; Bencherif et al., 2006; Seidel et al., 2001; Randel et al., 2000; Randel et Seidel, 2006; Randel et al., 2009, Oort et Liu, 1993). Based on the radiosonde datasets from 83 stations within the $\pm 30^{\circ}$ latitudinal belt between 1961 and 1990, Seidel et al. (2001) also found a cooling of $\sim 0.5 \mathrm{~K}$ per decade at the tropopause. More recently, over the southern tropics, a study by Bencherif et al. (2006) showed a significant cooling in the lower stratosphere. In fact, they used 22-years of observational upper-air data recorded from 1980 to 2001 over Durban $\left(30.0^{\circ} \mathrm{S}, 30.9^{\circ} \mathrm{E}\right)$, a South African site, and found a cooling of about $-1.09 \pm 0.41 \mathrm{~K}$ per decade in the lower stratosphere.

A large number of remote sensing instruments exist to measure atmospheric temperature: radiosonde, satellite, spectrometer, lidar, radar, etc. As regards method and cost, the measurements provided by radiosonde are a simple and effective tool for obtaining temperature profiles from ground up to an altitude of $\sim 30 \mathrm{~km}$ (Parker, 1985; Parker et al., 1997; Parker and Cox, 1995; Gaffen, 1993, 1996; Finger et al., 1995). Over the southern tropics and subtropics, very few studies on UT-LS and tropopause characteristics are available because there are very few stations. However, a limited number of stations have been operating in the southern hemisphere tropics and subtropics in the context of the SHADOZ (Southern Hemisphere ADditional OZonesondes) project since 1998 (Thompson et al., 2003). Reunion is one of these SHADOZ sites and offers one of the longest radiosonde-ozonesonde datasets in the southern tropics, going back to late 1992. Reunion is an overseas French Island in the Indian Ocean. It is an oceanic site located at $20.8^{\circ} \mathrm{S}$ in latitude and $55.5^{\circ} \mathrm{E}$ in longitude, about $800 \mathrm{~km}$ east of Madagascar.

Recently, a tropospheric ozone climatology and trend study over Reunion was carried out by Clain et al. (2009) us- ing this radiosonde-ozonesonde dataset. They found a positive ozone trend $(1.31 \pm 0.62 \mathrm{DU}$ per decade $)$ in the upper troposphere $(10-16 \mathrm{~km})$, between late 1992 and 2008. The results also covered the earlier ozone climatology reported over Reunion, based on both radiosonde/ozonesonde and Satellite data sets (Sivakumar et al., 2007). The above study is evidence of the quality of the dataset used.

In this paper, we investigate trends and variability of the tropopause and UT-LS temperatures, by analysing 16 years (1993-2008) of radiosonde data recorded at Reunion with a linear-regression fitting model (hereafter referred-to as Trend-Run). Trend-Run is a statistical model adapted at Reunion University for temperature trend estimates in the southern subtropical UT-LS region (Bencherif et al., 2006). For the present study, the model has been modified by considering the regional oceanic forcing. In order to examine the impact of regional oceanic forcing on trend estimates at the tropopause and UT-LS layers, temperature trends are estimated by taking into account the Indian Ocean Dipole (IOD).

The IOD corresponds to the inter-variability present into the Indian Ocean, with an east-west dipole in the SST anomalies of the basin. The mechanisms responsible for the IOD are not yet well known, but there are two assumptions. The first assumption is based on the fact that IOD is generated by a feedback coupled with ocean-atmosphere monsoon and tropical circulation (Saji et al., 1999), whereas the second considers IOD as part of an Indo-Pacific ENSO (Behera et al., 2002). Saji et al. (1999) have shown, from 40 years of observational data that this dipole mode accounts for about $12 \%$ of the SST variability in the Indian Ocean and causes severe rainfall in eastern Africa and droughts in Indonesia, in its active years. The IOD is associated with warm SST anomalies southeast of Madagascar and cold SST anomalies northwest of Australia during southern summers (Morioka et al., 2010). Recently, Morioka et al. (2010) have shown that the IOD is now accepted as a major climate mode in the southern Indian Ocean. Furthermore, Izumo et al. (2010) have suggested a possible connection between the antecedent IOD and ENSO. Based on a simple forecast model, Izumo et al. (2010) have suggested that a negative phase in the IOD anomaly is an efficient prediction of El Niño 14 months before its peak, and similarly, a positive phase of the IOD often precedes La Niña. Thereby, we have been careful in interpreting impact of IOD and ENSO on the time-evolution of mean monthly temperatures over Reunion. We decided to take into account this regional oceanic forcing mainly because of the results obtained by Rosenlof et al. (2008) over the western tropical Pacific Ocean, as mentioned above.

In addition, the present paper extends the results of the first study on the tropopause characteristics over Reunion, carried out by Sivakumar et al. (2006). In fact, the present study aims to treat the inter-annual variability and trend analysis coving a larger database and focuses on the temperature in the UTLS region. 
The paper is organized as follows: Section 2 provides a description of the data and the method used for linear trend calculation. Section 3 presents results obtained on temperature variability and trend results from the multi-regression TrendRun model. The summary and the conclusions are given in Sect. 4.

\section{Data and methods}

\subsection{Data and definitions}

The dataset used in this study is based on balloon-sonde temperature profiles recorded at Reunion by the OPAR (Observatoire de Physique de l'Atmosphère de la Réunion). It is a continuous and routine experiment that was initialized by the end of 1992 with a fortnightly frequency within the NDACC (Network for the Detection of Atmospheric Composition Change) project. By January 1999, Reunion was included in the SHADOZ network, and the frequency of radiosonde experiments increased, becoming weekly. Details concerning the SHADOZ program are available from Thompson et al. (2003a, b, 2007).

Indeed, the Reunion radiosonde contains one of the longest-term datasets for ozone and temperature in the southern tropics. The present study uses 404 radiosonde temperature profiles, recorded over a 16-year period from January 1993 to December 2008. The total number of profiles ranges between 21 and 38 per year. It therefore corresponds to 16 years of continuous and homogenous observations. In this study, we have interpolated the measured radiosonde temperature profiles with a $50 \mathrm{~m}$ vertical resolution at an altitude range from 0 to $30 \mathrm{~km}$.

A radiosonde set carries three different sensors to measure in situ parameters, i.e., pressure, temperature and relative humidity. In order to measure the associated partial pressure of ozone, an Electrochemical Concentration Cell is added. Radiosonde experiments enable measurements of temperature profiles from ground up to burst-balloon altitude, which is at $\sim 30-35 \mathrm{~km}$. At Reunion station, Väisälä RS80 sondes have been used until October 2006. By 2007, the radiosonde experimental set was upgraded. Since then, the M2K2-DC Modem system has been used. Comparisons between RS80 Väisälä sonde and M2K2-DC Modem have been made, and this comparison revealed a very good agreement between the temperature profiles. The largest difference was observed at the end of 6 April 2010 profiles and was less than $3 \mathrm{~K}$ (SHADOZ Newsletter, 2010). As our study focuses on the UT-LS region, we can consider that the change in sonde model have not any consequence on our regression analysis.

In order to check the quality of the data, the Reunion radiosonde system is part of the JOSIE (Julich OzoneSonde Intercomparison Experiment) process. This intercomparison campaign, which comes under the World Meteorology Organization, is aimed at assessing the performances of radiosonde systems through intercomparison using a standard reference instrument (Thompson et al., 2007).

The purpose of the present study is to examine temporal evolution of temperature at the tropopause and in the UTLS. The tropopause is examined in terms of the Lapse Rate Tropopause (LRT) and the Cold Point Tropopause (CPT), while the Lower Stratosphere (LS) is examined in terms of the averaged temperature between the 18 and 19-km layers and the Upper Troposphere (UT) is examined in terms of the averaged temperature between the 14 and 15-km layers. The tropical Cold Point Tropopause is a key parameter that controls the entrance of tropospheric air into the stratosphere, particularly as regards water vapour (Randel et al., 2006, Rosenlof et al., 2008). CPT is defined as the altitude where the minimum temperature is found below $20 \mathrm{~km}$. The Lapse Rate Tropopause represents the standard World Meteorology Organization definition of the tropopause. It corresponds to a decrease of the temperature lapse rate not ex-

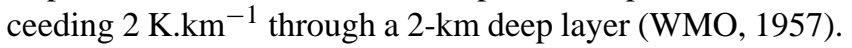

\subsection{The Trend-Run model}

Trend analyses are based on a linear regression fitting model called Trend-Run. It is adapted from the AMOUNTS (Adaptive MOdel UNambiguous Trend Survey) and AMOUNTSO3 models, developed for ozone and temperature trend assessments (Hauchecorne et al., 1991, Keckhut et al., 1995; Guirlet et al., 2000). The Trend-Run is hence a statistical model that has been adapted and used at Reunion University for temperature trend estimates in the southern subtropical UTLS (Bencherif et al., 2006). The model is based on the principle of breaking down the variations of a time series $Y(t)$ into the sum of different parameters that explain the variations of $Y(t)$ :

$Y(z, t)=c_{1} \mathrm{SAC}(z, t)+c_{2} \mathrm{AC}(z, t)+c_{3}(z) \mathrm{QBO}\left(z_{-} 40, t\right)$
$+c_{4}(z) \operatorname{ENSO}(t)+c_{5}(z) \operatorname{SSN}(t)+\varepsilon(z, t)$

where $\varepsilon$ is the residual term, assumed to consist of trend and noise.

When the coefficients $c_{i(i=1 t o 5)}$ are calculated, the corresponding parameters are removed from the studied geophysical signal $Y(t)$. The model then applies the least-square method in order to minimize the sum of the residual squares and to determine the parameter coefficients $c_{i}$. Regarding the trend, it is parameterised as linear: $\operatorname{Trend}(t)=\alpha_{0}+\alpha_{1} . t$, where $t$ denotes the time range, $\alpha_{0}$ is a constant, $\alpha_{1}$ is the slope of Trend(t) line that estimates the trend over the time scale.

In its initial version, as used by Bencherif et al. (2006), the Trend-Run model considers the main forcings, i.e., annual and semi-annual cycles, QBO (quasi-biennal oscillation), ENSO (El-Nino Southern Oscillation), and the 11-years solar cycle (Sun-Spot Number). Annual and Semi-Annual Cycle (AC, SAC) are taken as being the mean seasonal cycles. 
Moreover, we used the monthly mean zonal wind speed at Singapore at 40-hPa level and the Southern Oscillation Index to parameterize the QBO (Randel et al., 1994, Li et al., 2008) and the ENSO cycles respectively, while the 11-year solar cycle is defined as a linear function correlated with the solar flux at $10.7 \mathrm{~cm}$. With regard to QBO, its maximum forcing generally occurs at $20 \mathrm{hPa}$ (Naujokat et al., 1986, Politowictz et al., 1997). Furthermore, Naujokat et al. (1986) showed from wind data that the $50 \mathrm{hPa}$ is the best level for correlation between QBO and tropopause. Hence, we considered the $40 \mathrm{hPa}$ as a reference level for the QBO index, in order to obtain a significant QBO signal and, at the same time, to be close enough to the tropopause.

In order to examine the hypothetic link between regional oceanic forcing as well as the temperature trend estimate at tropopause and the UT-LS layer, the Trend-Run model has been modified by introducing the Indian Ocean Dipole (IOD).

The model equation therefore becomes:

$$
\begin{aligned}
& Y(z, t)=c_{1} \cdot \operatorname{SAC}(z, t)+c_{2} \mathrm{AC}(z, t)+c_{3}(z) \mathrm{QBO}\left(z_{-} 40, t\right) \\
& +c_{4}(z) \operatorname{ENSO}(t)+c_{5}(z) \operatorname{SSN}(t)+c_{6}(z) \operatorname{IOD}(t)+\varepsilon(z, t)
\end{aligned}
$$

Motivation for including the IOD as a potential force of change at tropopause and UT-LS is based on the fact that ocean-atmosphere interactions, through convective activity, are believed to play an important role in climate change (Saji et al., 1999, Yamagata et al, 2004). Recently, Rosenlof et al. (2008) examined trends in the temperature of the tropical lower stratosphere from several radiosonde sites in the western tropical Pacific Ocean. Their result suggests that sea surface anomalies have an influence on temperature variations at the tropopause and in the lower stratosphere. Similarly, in the present trend estimate, we intend to examine effects of Indian Ocean anomalies over the Indian Ocean region by introducing the IOD. The IOD is characterized by a positive phase when SST (Sea Surface Temperature) is abnormally cooled in the eastern equatorial Indian Ocean and abnormally warmed in the western equatorial Indian Ocean, and with a negative phase when the conditions are opposite (Behera et al, 2002). The IOD is commonly measured by an index called the Dipole Mode Index (DMI), which it is defined as the SST anomaly difference between the western $\left(50^{\circ} \mathrm{E}-70^{\circ} \mathrm{E}, 10^{\circ} \mathrm{S}-10^{\circ} \mathrm{N}\right)$ and eastern $\left(90^{\circ} \mathrm{E}-\right.$ $\left.110^{\circ} \mathrm{E}, 10^{\circ} \mathrm{S}-\mathrm{Equator}\right)$ tropical Indian Ocean. In order to consider IOD in the Trend-Run model, we used DMI from www.jamstec.go.jp/frsgc/research/d1/iod.

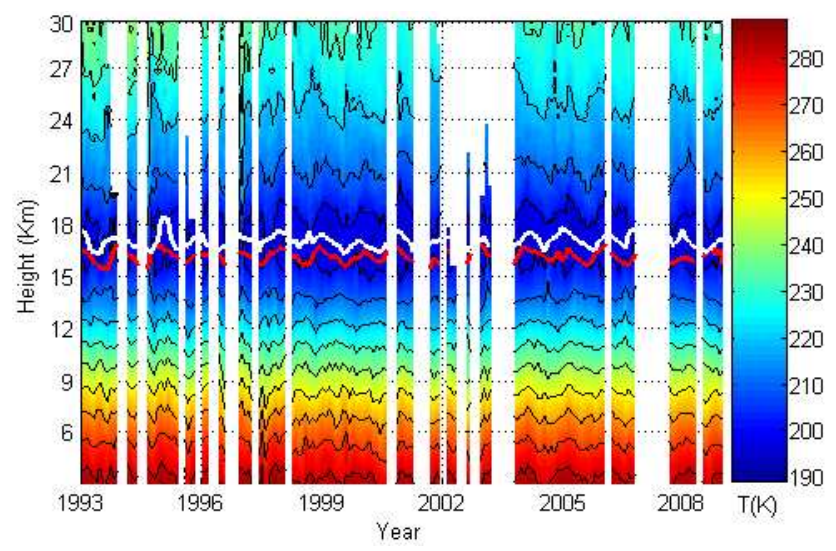

Fig. 1. Evolution of the temperature time series from January 1993 to December 2008 over Reunion with CPT (white) and LRT (red).

\section{Results and discussion}

\subsection{Monthly climatological temperature}

For trend estimation, temperature profiles have been reduced into monthly averaged profiles. Figure 1 shows the resulting time-height cross-section, with the corresponding thermal tropopause (LRT, CPT) altitude superimposed. It can be noticed that some profiles are vertically limited and others are not recorded as a result of technical or unfavourable meteorological conditions. The ratio of missing monthly profiles is estimated at $\sim 22 \%$. Moreover, this figure confirms the fact that the tropopause is not a static layer of the atmosphere. Indeed, Fig. 1 illustrates the inter-annual variability of the thermal tropopause altitude from January 1993 to December 2008. In order to fill the gaps, we computed and used the monthly climatological temperatures at UT, LRT, CPT and LS, derived from the Reunion dataset covering this period.

The monthly climatological temperature values and the corresponding standard deviation are indicated in Fig. 2 and reported in Table 1. Figure 2a shows that seasonal variations of temperature at CPT and LRT are well correlated (0.97), and the CPT appears on average $2 \mathrm{~K}$ colder than the LRT. The minimum temperatures at CPT and LRT are $193.9 \mathrm{~K}$ and $195.8 \mathrm{~K}$, respectively, and both appear during southern summer (December-February), whereas the maximum temperature appears during September, with 198.6 K and 200.3 K respectively. Furthermore, Fig. 2a shows a dominant annual cycle at LRT, CPT and LS altitudes over Reunion Island. This corresponds to results obtained by Bencherif et al. (2006) for Durban $\left(30.0^{\circ} \mathrm{S}, 30.9^{\circ} \mathrm{E}\right)$. They reported on temperature climatology and trend estimates through the use of a 22-year upper-air dataset, and found that the annual cycle is the most dominant forcing with maximum amplitude at tropopause level and in the lower stratosphere. Figure 2a shows that at UT, the annual cycle is less important than for 
Table 1. Monthly mean climatological temperature and corresponding standard deviations (in Kelvin) at UT, LRT, CPT and LS from radiosonde data collected at Reunion from January 1993 to December 2008.

\begin{tabular}{lllll}
\hline & UT $14-15 \mathrm{~km}(\mathrm{~K})$ & LRT $(\mathrm{K})$ & CPT $(\mathrm{K})$ & LS 18-19km $(\mathrm{K})$ \\
\hline January & $205.1 \pm 2.2$ & $195.8 \pm 1.8$ & $193.9 \pm 2.3$ & $197.2 \pm 3.7$ \\
February & $205.3 \pm 2.0$ & $195.3 \pm 2.7$ & $193.4 \pm 3.0$ & $197.6 \pm 2.7$ \\
March & $205.5 \pm 1.7$ & $196.0 \pm 1.9$ & $193.9 \pm 1.6$ & $197.4 \pm 1.8$ \\
April & $205.9 \pm 1.6$ & $196.9 \pm 2.6$ & $195.4 \pm 2.6$ & $198.5 \pm 1.7$ \\
May & $207.1 \pm 1.4$ & $198.3 \pm 3.4$ & $195.3 \pm 1.2$ & $198.2 \pm 2.1$ \\
June & $206.9 \pm 1.5$ & $198.1 \pm 1.6$ & $196.1 \pm 1.1$ & $200.3 \pm 1.3$ \\
July & $206.4 \pm 1.4$ & $198.1 \pm 1.6$ & $196.2 \pm 0.8$ & $201.0 \pm 1.5$ \\
August & $206.7 \pm 1.7$ & $198.7 \pm 1.7$ & $197.0 \pm 1.5$ & $202.4 \pm 1.5$ \\
September & $206.7 \pm 2.7$ & $200.3 \pm 1.6$ & $198.6 \pm 2.0$ & $202.3 \pm 3.0$ \\
October & $207.1 \pm 2.2$ & $199.4 \pm 1.5$ & $197.6 \pm 1.3$ & $202.0 \pm 1.7$ \\
November & $206.6 \pm 1.3$ & $198.7 \pm 2.5$ & $196.7 \pm 2.1$ & $199.1 \pm 1.9$ \\
December & $204.6 \pm 1.8$ & $196.9 \pm 1.7$ & $194.7 \pm 0.9$ & $199.2 \pm 1.2$ \\
\hline
\end{tabular}

a)

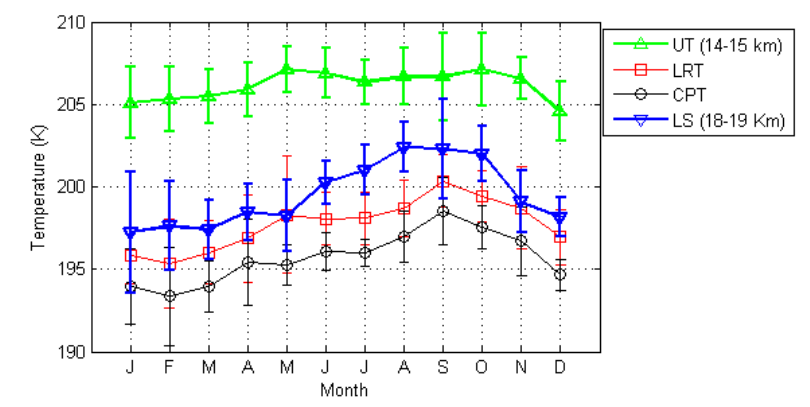

b)

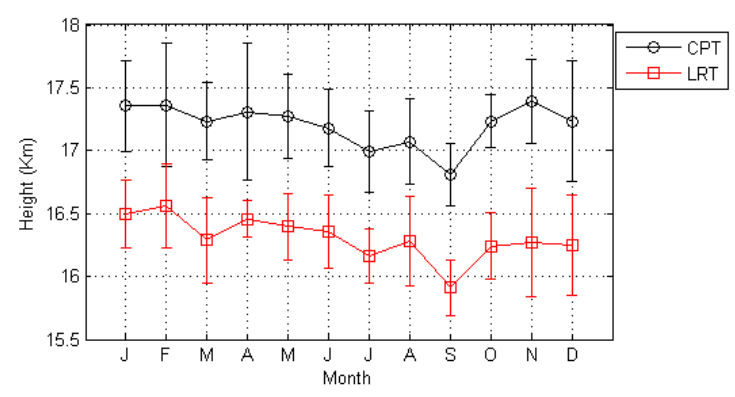

Fig. 2. (a) Time evolution of monthly averaged temperature at UT (14-15 km), LRT, CPT and LS (18-19 km) over Reunion derived from continuous observations during the period from January 1993 to December 2008. (b) Time evolution of monthly averaged heights of LRT and CPT over Reunion from the same period of observations as (a).

the upper layers (LRT, CPT and LS). Figure 2b shows that seasonal variations of CPT and LRT heights are highly correlated (0.84), but the CPT appears on average $0.91 \pm 0.15 \mathrm{~km}$ higher than the LRT. This corresponds to results reported earlier by Sivakumar et al. (2006) for Reunion, where they found that the CPT appears $1.09 \pm 0.94 \mathrm{~km}$ higher than the
LRT. The CPT and LRT are lowest (CPT at $16.8 \mathrm{~km}$ and LRT at $15.9 \mathrm{~km}$ ) in September, while they are at their highest (CPT at $17.4 \mathrm{~km}$ and LRT at $16.7 \mathrm{~km}$ ) during the southern summer. The obtained monthly variations over Reunion are quite similar to the results obtained by Seidel et al. (2001). In fact, based on the radiosonde datasets from 83 stations within the $\pm 30^{\circ}$ latitudinal belt between 1961 and 1990, Seidel et al.(2001) found that the tropopause is highest (about $17 \mathrm{~km}$ ) and coldest (about $191 \mathrm{~K}$ ) during southern summer, while it is lowest (about $16.3 \mathrm{~km}$ ) and warmest (about $195 \mathrm{~K}$ ) during southern winter.

\subsection{Temperature variability}

A statistical parameter that is used to quantify how well the regression fitting model describes the data is the coefficient of determination $R^{2}$. It is defined as the ratio of regression sum of squares to the total sum of squares. The coefficient of determination measures the proportion of the total variation in temperature in time, explained by the regression model. When the regession model very clearly explains the total variation in the geophysical signal $Y(t)$, the value of $R^{2}$ is close to unity; on the other hand, when the model does not resolve all the variations, $R^{2}$ tends to zero (Pastel et al., 2007). Figure 3 depicts the time-evolution of mean monthly temperatures at CPT over Reunion from radiosonde observations (blue line) and the corresponding simulation from the Trend-Run regression model (red line). The coefficient of determination obtained for CPT variations is high, i.e., $\sim 0.80$, and suggests that the model correctly reproduces most of the variability of the studied temperature signal.

As was explained by Bencherif et al. (2006), the degree of data independency is estimated through the autocorrelation coefficient $\varphi$ of the residual. The latter should be low for a good estimation of trend (Weatherhead et al., 1998, Tiao et al., 1990). In this study, trend and coefficient $c_{i}$ uncertainty 
Table 2. Contribution and corresponding standard deviations (in percentages) of SAC, AC, QBO, IOD, ENSO and 11-year solar cycle to temperature variability at UT $(14-15 \mathrm{~km}), \mathrm{LRT}, \mathrm{CPT}$ and in the LS $(18-19 \mathrm{~km})$, as obtained by the linear regression Trend-Run model. The last line gives the corresponding values for the coefficient of determination, $R^{2}$.

\begin{tabular}{lllll}
\hline & UT 14-15 km $(\%)$ & LRT $(\%)$ & CPT $(\%)$ & LS 18-19 km $(\%)$ \\
\hline SAC & $5.5 \pm 1.9$ & $10.2 \pm 4.3$ & $8.1 \pm 2.9$ & $9.1 \pm 2.3$ \\
AC & $10.5 \pm 1.9$ & $45.0 \pm 4.6$ & $32.0 \pm 3.1$ & $26.0 \pm 2.4$ \\
QBO & $4.9 \pm 2.9$ & $9.6 \pm 6.7$ & $11.2 \pm 4.6$ & $6.2 \pm 3.7$ \\
IOD & $4.4 \pm 4.8$ & $6.0 \pm 10.9$ & $12.3 \pm 7.6$ & $13.1 \pm 5.9$ \\
ENSO & $12.1 \pm 5.9$ & $5.2 \pm 13.3$ & $13.0 \pm 9.2$ & $11.2 \pm 7.3$ \\
SSN & $14.6 \pm 5.7$ & $2.0 \pm 12.9$ & $3.4 \pm 8.9$ & $8.8 \pm 7.1$ \\
$R^{2}$ & 0.52 & 0.78 & 0.80 & 0.74 \\
\hline
\end{tabular}

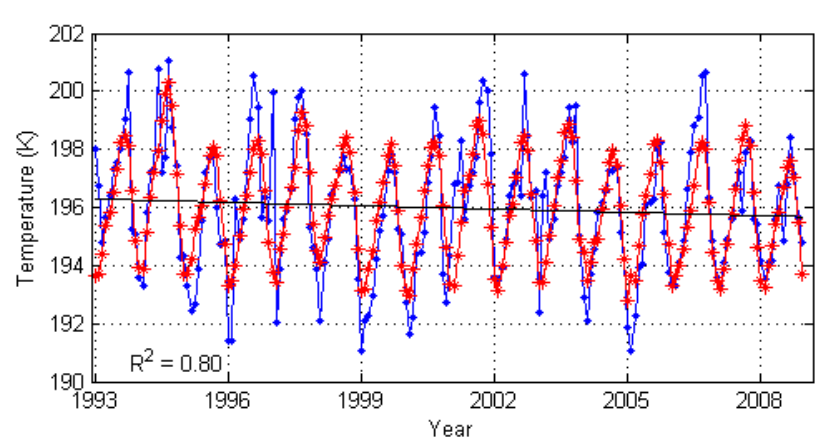

Fig. 3. Time evolution of monthly temperature values as observed over Reunion Island at CPT from January 1993 to December 2008 (blue line), the superimposed red star line represents CPT values as simulated by Trend-Run regression model, while the straight black line illustrates the obtained temperature trend at CPT. The corresponding coefficient of determination $R^{2}$ is shown, $R^{2}=0.80$.

are derived by taking into account the autocorrelation coefficient $\varphi$, as shown in the appendix of Logan et al. (1994), this uncertainty is given by equation 3 .

$\sigma_{a}^{2}=v(k) \cdot \sigma_{s}^{2} \cdot \frac{1+\varphi}{1-\varphi}$

In Eq. (3) $\sigma_{s}^{2}$ represents the variance of the residual term and $v(k)$ represents the covariance matrix of different forcings taken into account by the regression model.

Table 2 summarizes the values of contribution coefficients $c_{i}$ and corresponding standard deviation for SAC, AC, QBO, IOD, ENSO and SSN forcings, together with values of the coefficient of determination $R^{2}$ at UT, CPT, LRT and LS. All the corresponding coefficients of determination are higher than 0.70 , except the one for the UT layer: $R^{2}(\mathrm{UT})=0.52$. The highest value 0.80 is obtained at CPT, while $R^{2}$ is $\sim 0.78$ and $\sim 0.73$ at LRT and LS, respectively. This suggests that the regression model Trend-Run quite precisely explains the variability of the temperature over time. As certain geophysical processes, such as volcanic aerosol loading, are not taken into account by the model, obviously part of the variability may not be explained.

As expected, the dominant component of the thermal structures in the local UT-LS is the AC. In fact, AC is found to explain more than $26.0 \pm 2.4 \%$ of the temperature variation at LRT, CPT and LS. The influence of the AC on temperature variation is the highest at LRT $(45.0 \pm 4.6 \%)$. Regarding the SAC, its maximum influence, i.e. $10.2 \pm 4.3 \%$, is located at LRT. As one may expect in the UT-LS region, the influence of the AC on temperature variation is about 3-4 times stronger than the influence of the SAC. This corresponds to results obtained over Durban using 22-years of observational upper-air data recorded from 1980 to 2001 (Bencherif et al., 2006). Indeed, the seasonal variations of temperature at the tropopause over Reunion are mostly driven by the $\mathrm{AC}$ with the coldest temperature and the highest tropopause height during southern summer and the warmest temperature with the lowest tropopause height during the southern winter (Fig. 2a, b). However, this table shows that the cumulative influence of the oceanic forcings (IOD and ENSO) is quite important. Indeed, about $12.1 \pm 5.9 \%$ of the temperature variation is explained by ENSO, compared to about $10.5 \pm 1.9 \%$ by AC at UT.

From Trend-Run analyses, about $10 \pm 4.3 \%$ of temperature variability at tropopause may be explained by the QBO forcing (see Table 2). This result is fairly close to the one obtained by Randel et al. (2000) for the inter-annual variability of the tropical tropopause derived from radiosonde of 26 stations and NCEP reanalyses (period: 1979-1997). They found that $12 \%$ of the inter-annual variance of the tropopause temperature is explained by the QBO. Nevertheless, in the lower stratosphere, the QBO contributes $\sim 6.2 \pm 3.7 \%$ to temperature variability, less than at LRT and CPT.

Two oceanic forcings are included in our regression model: the ENSO and the IOD forcings. The highest contribution of ENSO and IOD is found at CPT and LS: IOD explains $12.3 \pm 7.6 \%$ and $13.1 \pm 5.9 \%$ respectively of the interannual variability of temperature. They thus admit contributions larger than that of the QBO at these two layers. 
However, this table shows that $12.1 \pm 5.9 \%$ of the inter-annual variability of temperature at UT is explained by ENSO. This result corresponds to past works reported by Reid and Gage (1985). They showed that inter-annual variations in the tropical tropopause are linked to the ENSO. Besides, this result suggests that temperature at CPT and LS have significant connections with the underlying sea surface forcing. This is consistent with the findings of Rosenlof et al. (2008). Indeed, Rosenlof et al. (2008) examined trends in the temperature of the tropical lower stratosphere from several radiosonde sites on the so-called warm pool region of the western tropical Pacific Ocean. They found a significant anti-correlation between stratospheric temperature anomalies and sea surface temperature anomalies in the western tropical Pacific Ocean. They concluded that convection may therefore be a link between the ocean and the LS. In our case, the result strongly suggests that the underlying Indian Ocean can have a fairly important influence on temperature variability at CPT and LS layers.

In the second step of our analysis, the seasonal cycles (SAC, AC) have been removed in order to emphasize the influence of the other parameters, particularly the influence of the two oceanic forcings at CPT and LS. Figure 4a shows that IOD (red line) and the temperature anomalies at CPT (blue line) are slightly correlated (0.15), whereas ENSO and the temperature anomalies at CPT are slightly anti-correlated (-0.20) (Fig. 4b). Temperature anomalies are derived on a monthly mean basis by subtracting the long-term average temperatures for each calendar month of the year (shown in Figure 2) from the monthly mean values. The same analysis has been carried out for the other layers. The results obtained show that IOD and the temperature anomalies at tropopause (LRT, CPT), and overall the UT-LS, are slightly correlated, in the range of $0.08-0.15$, with the maximum of correlation at CPT. As a result, for ENSO, we obtained a low anti-correlation in the range of $0.06-0.21$ for the tropopause and UT layers, with the maximum anti-correlation at UT $(-0.21)$, whereas ENSO and the temperature anomalies at LS are slightly correlated (0.10). Similarly, as reported by Rosenlof et al., (2008), the cross correlation between the monthly temperature anomalies at the $70 \mathrm{hPa}$ level (LS) over Koror $\left(7.3^{\circ} \mathrm{N}, 134.5^{\circ} \mathrm{E}\right)$ and the SST anomalies of the equatorial western Pacific warm pool in the 1960-1993 period is about -0.15 .

Reunion observations and results suggest that the interannual variation of temperature at tropopause and broadly in the subtropical UT-LS is slightly linked to oceanic forcings.

\subsection{Linear trend estimates}

Aerosols constitute a source of uncertainty which may affect the temperature trend estimate, notably following a major volcanic eruption, because of their role in the thermal balance. The eruption of Pinatubo in June 1991 caused the largest disturbance of the $20^{\text {th }}$ century in the stratosphere a)

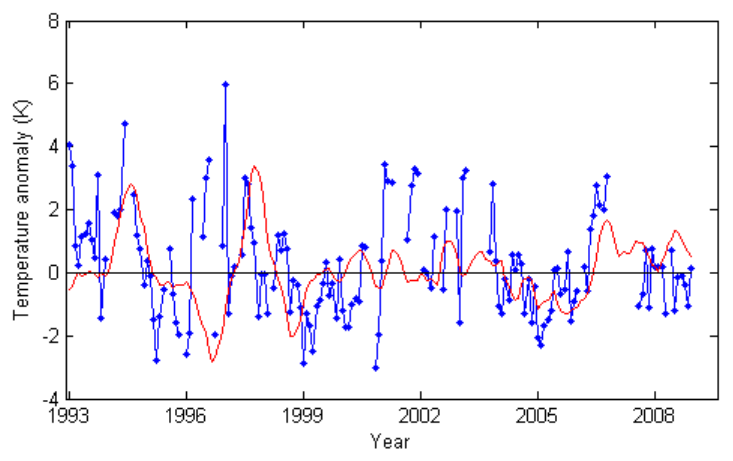

b)

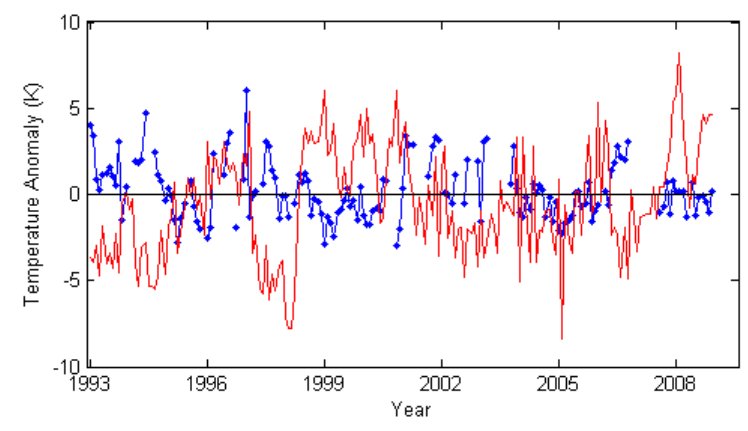

Fig. 4. Time evolution of deseasonalised monthly averaged temperature at CPT (blue line) over Reunion derived from continuous observations during the period from January 1993 to December 2008, together with (a) Indian Ocean Dipole (IOD) component as parameterized in the regression analysis (red line) and with (b) ENSO component as parameterized in regression analysis (red line).

(McCormick et al. 1995). A $1 \mathrm{~K}$ global temperature increase in the lower stratosphere at $50 \mathrm{hPa}$ was observed after the eruptions of El Chichón and Pinatubo (WMO, 2006). Bencherif et al. (2003) indicated from SAGE II data that the amount of volcanic aerosol in the southern subtropical UT-LS decreased gradually to return to its normal level by late 1995 and early 1996. Consequently, in order to avoid introducing bias in temperature trend estimates due to aerosol loading, the post-Pinatubo temperature values (January 1993-December 1995) have been discarded, thereby reducing the trend analysis for the period between January 1996 and December 2008. However, in order to examine the impact of the IOD and volcanic aerosols on temperature trend estimates, the regression model Trend-Run is used, following different applications with or without IOD forcing, and with or without the post-Pinatubo dataset.

Figure 5 depicts the time evolution of mean monthly temperature in the LS with and without post-Pinatubo dataset over Reunion, with the cooling trend lines superimposed. This figure illustrates more important cooling with post-Pinatubo dataset $(-1.31 \pm 0.33 \mathrm{~K}$ per decade) than without post-Pinatubo dataset $(-0.90 \pm 0.40 \mathrm{~K}$ per decade). 
Table 3. Temperature trends (in Kelvin per decade) at UT, LRT, CPT and LS as computed by the Trend-Run model from radiosonde observations at Reunion Island. The model takes into account AO, SAO, QBO, ENSO and 11-year solar cycle. This table illustrates temperature trends with (first and third column) and without (second and fourth column) including the IOD forcing in the model, and with (first and second column) and without (third and fourth column), taking into account the post-Pinatubo data. The averaged coefficient of determination $R^{2}$ is about 0.75 .

\begin{tabular}{lllll}
\hline & with IOD/with Pinatubo & without IOD/with Pinatubo & with IOD/without Pinatubo & without IOD/without Pinatubo \\
\hline LS & $-1.31 \pm 0.33$ & $-1.22 \pm 0.33$ & $-0.90 \pm 0.40$ & $-0.69 \pm 0.40$ \\
CPT & $-0.38 \pm 0.33$ & $-0.30 \pm 0.34$ & $-0.36 \pm 0.48$ & $-0.16 \pm 0.48$ \\
LRT & $-0.52 \pm 0.35$ & $-0.49 \pm 0.35$ & $+0.12 \pm 0.39$ & $+0.15 \pm 0.44$ \\
UT & $-0.37 \pm 0.27$ & $-0.34 \pm 0.27$ & $-0.12 \pm 0.35$ & $-0.12 \pm 0.34$ \\
\hline
\end{tabular}

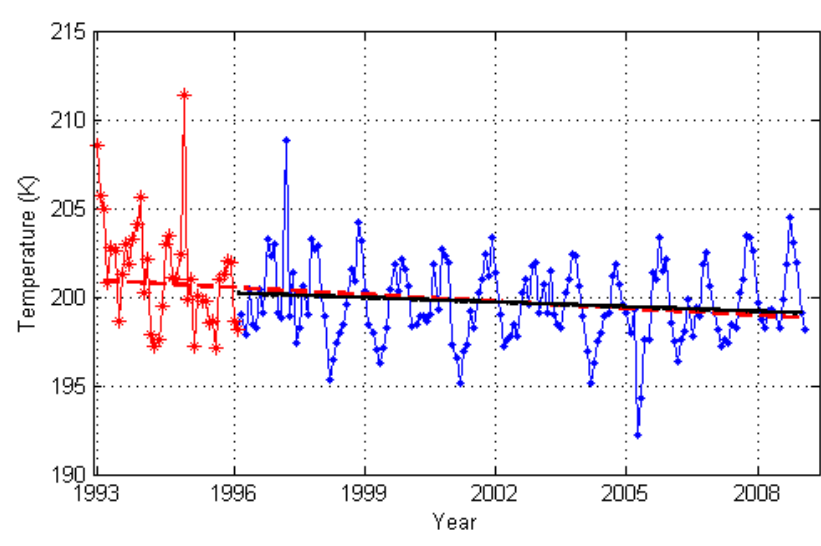

Fig. 5. Time evolution of the monthly averaged temperature values in the lower stratosphere $(18-19 \mathrm{~km})$ with the post-Pinatubo data (red star line) and the without post-Pinatubo data (blue line). The superimposed cooling trend line obtained with the post-Pinatubo data (dash red line) and the cooling trend line obtained without the post-Pinatubo data (black line).

Additionally, this result highlights significant cooling in the lower stratosphere over Reunion.

This cooling in the lower stratosphere is quite similar to results obtained by Bencherif et al. (2006) for Durban $\left(30.0^{\circ} \mathrm{S}, 30.9^{\circ} \mathrm{E}\right)$. Based on a 22 -year period temperature radiosonde data, they found that the maximum cooling rate is $1.09 \pm 0.41 \mathrm{~K}$ per decade, and is observed in the lower stratosphere, at $70 \mathrm{hPa}$. Moreover, the significant cooling in the lower stratosphere corresponds to other studies (Oort and Liu 1993, Angell 1988). Based on the global rawinsonde network of more than 700 stations, Oort and Liu have found significant cooling of about $-0.43 \pm 0.16 \mathrm{~K}$ per decade in the lower stratosphere (period: 1964-1988).

Table 3 shows temperature trends in the UT-LS obtained with and without including the IOD forcing in the model, with and without taking into account the post-Pinatubo data. The first column shows temperature trends obtained at UT, LRT, CPT and LS with IOD and post-Pinatubo data included, the second column is similar to the first one but without IOD, the third column is also similar to the first one but without taking into account the post-Pinatubo data, and the fourth column is similar to the third but without IOD. Note that in all situations, the model has a good coefficient of determination $R^{2}$, i.e., $R^{2}$ is within 0.73 and 0.80 , except at UT where $R^{2}$ is relatively weak $(\sim 0.52)$. The results confirm the possibility that trend analyses may be biased by the postPinatubo dataset if not removed, notably in the LS. Indeed, in the LS difference in temperature trends, whether postPinatubo data is taken into account or not, is in the range of $0.32-0.41 \mathrm{~K} /$ decade (Table 3 ). However, the results show that at CPT, the difference between temperature trends with and without taking into account the post-Pinatubo data is weak: $\sim 0.02 \mathrm{~K}$ per decade. Moreover, Randel et al. (2000) showed that the effect of Pinatubo is less distinctive at the tropopause, particularly when applying the radiosonde average and it is difficult to isolate in individual station record.

In general, Table 3 highlights a cooling in the LS, tropopause and UT. However, temperature trends obtained at tropopause (CPT, LRT) and at UT are not significant except for calculatiing trend with IOD and post-Pinatubo data, probably because of the length of time covered by the data. Tiao et al. (1990) have shown that the precision of trend determination greatly depends on the variability of individual observations, on the autocorrelation of the observation and on the length of the data record. In fact, our result shows a non-significant warming trend at LRT of about $0.12 \pm 0.39 \mathrm{~K}$ per decade. Seidel et al. (2001) observed, from radiosonde data recorded over 20 stations within $\pm 15^{\circ}$ for the period 1978-1997, a cooling of about $-0.5 \mathrm{~K}$ per decade at LRT. However, at Kota Kinabalu $\left(5.9^{\circ} \mathrm{N}, 116.1^{\circ} \mathrm{E}\right)$ they found a positive trend at the LRT of about $0.11 \mathrm{~K}$ per decade. In addition, Randel et al. (2000) with radiosonde data found negative trends of $-0.5 \mathrm{~K}$ per decade during 1979-1997 at LRT, whereas they found with NCEP data a non-significant positive trend at LRT of about $0.04 \pm 0.22 \mathrm{~K}$ per decade during the same period. In the same way, our results show a non-significant cooling trend at UT: $0.12 \pm 0.35 \mathrm{~K}$ per decade. Furthermore, Oort et al. (1993) considered the long-term trends from global rawinsonde network (period: 
1964-1988). They obtained a cooling trend: $-0.11 \pm 0.11 \mathrm{~K}$ per decade at UT in the southern hemisphere. More recently, Bencherif et al. (2006), from radiosonde data at Durban for the period 1980-2001, showed a cooling of about $-0.10 \pm 0.18 \mathrm{~K}$ per decade at UT.

It is however clear from Table 3 that only temperature trend in the LS is significant for both situations with or without post-Pinatubo data. We obtained a cooling of about $1.31 \pm 0.33 \mathrm{~K}$ per decade and $-0.90 \pm 0.40 \mathrm{~K}$ per decade respectively with and without post-Pinatubo data. We can suppose that the strong, statistically significant LS cooling of both experiments is consistent with an ozone change in the stratosphere. Indeed the eruption of Pinatubo has significantly affected global ozone and temperature (McCormick et al., 1995). Furthermore, one of the most significant factors that affect temperature trends, notably in the LS, is large aerosol enhancement following a volcanic eruption (WMO, 1995). With reduced ozone, the LS cools between -0.5 to $-1.0 \mathrm{~K}$ per decade in northern and southern middle- and high- latitudes (Langematz et al., 2003). Ozone absorbs shortwave radiation mainly in the stratosphere, where it dominates shortwave heating, and emits longwave radiation leading to warming of the LS, hence less ozone leads to a cooling of the LS. However, other gases may also play a role in the variability of the temperature of the stratosphere, particularly carbon dioxide $\left(\mathrm{CO}_{2}\right)$ (Pitari et al., 1992, Langematz et al., 2003). Indeed, the increasing concentration of carbon dioxide in the atmosphere has two distinct predicted effects: on the one hand, it increases the tropospheric temperature and on the other hand it cools the stratosphere (Pitari et al., 1992). As reported by Randel et al. (2009), trends in middle and upper stratosphere derived from Stratospheric Sounding Unit, taking into account effects due to $\mathrm{CO}_{2}$ changes, shows mean cooling of $0.5-1.5 \mathrm{~K}$ per decade during 19792005, with the greatest cooling in the upper stratosphere near $40-50 \mathrm{~km}$. Based on the simulation of a general circulation model of the troposphere, stratosphere and mesosphere, Langematz et al. (2003) suggested that the observed upper stratosphere temperature trends during the past two decades in low to middle latitudes are caused by radiative effects due to ozone and $\mathrm{CO}_{2}$ changes. However, they also suggested that other effects than ozone and $\mathrm{CO}_{2}$ changes must be considered to fully explain the observed temperature changes in the LS. Indeed from the result of the temperature variability (mentioned in subsection 3.2), we can suggest that the SST changes can be considered, in addition to the effects of ozone and $\mathrm{CO}_{2}$ changes, when explaining the temperature changes observed in the LS.

In fact, in the LS, inclusion of the IOD component in the regression analysis makes a difference in the inferred temperature trend of $\sim 0.16 \pm 0.05 \mathrm{~K}$ per decade. From Table 3 , it can be seen that at LRT and UT there is almost no difference between temperature trends with and without IOD, whereas at CPT and LS, results are different. This corroborates the IOD effect on temperature variability and trend estimates at CPT and in the LS, and suggests that IOD forcing contributes to increasing the rate of cooling of about $0.16 \pm 0.05 \mathrm{~K}$ per decade in the LS. Consequently, we can say that IOD should be taken into account for the calculation of temperature trends in the LS and at CPT. These results support the assumption that the Indian Ocean may have an impact on temperature variability and change in the UT-LS.

\section{Summary and conclusion}

This paper deals with trends and variability of the UTLS temperatures over a southern subtropical site. The study mainly focuses on analysis of temperature profiles derived from balloon-sonde experiments at Reunion $\left(20.8^{\circ} \mathrm{S}\right.$, $55.5^{\circ} \mathrm{E}$ ) during the January 1993-December 2008 period. The Reunion dataset is an original and useful one to study UT-LS characteristics and changes. There are in fact a very few operating sites in the southern tropics, and the Reunion dataset is the longest one.

Trend analyses are based on a linear multi-regression fitting model called Trend-Run. The general purpose of the use of multi-parameter regression analysis is to examine impact of several geophysical cycles and forcings on variability of thermal structures at tropopause and broadly the observed subtropical UT-LS region. In order to examine a possible links between the Indian Ocean forcing and temperature trend estimates, the Trend-Run model has been modified to take into account the IOD forcing. Indeed, the IOD represents the inter-annual variability present in the Indian Ocean with an east-west dipole in the SST anomaly of the basin. More than $70 \%$ of the variability of temperature at tropopause (CPT, LRT) and in the LS is reproduced by the Trend-Run model.

Our results show that the $\mathrm{AC}$ is the main component in the variability of temperature at tropopause and UT-LS temperature over Reunion. In fact more than $26 \pm 2.4 \%$ of the variation of temperature at tropopause and in the LS can be explained by AC. Furthermore, we note that the influence of IOD on the variability of temperature shows the highest ratio at CPT and LS. In fact, at CPT, $12.3 \pm 7.6 \%$ of the variation of temperature can be explained by IOD, whereas at LS, this increases to $13.1 \pm 5.9 \%$. This result suggests that the underlying Indian Ocean may have an influence on the variability of the thermal structures at CPT and LS.

In the present study, the Trend-Run model is applied to selected layers and altitudes in the UT-LS region: UT, LRT, CPT and LS. The trend estimates are examined with or without including IOD and post-Pinatubo data. Temperature trends at tropopause and UT are not significant except for the calculation with the full dataset, i.e., with post-Pinatubo. This result confirms the fact that the precision of trend determination may depend on aerosol loading in the UT-LS and on the length of the data record (Tiao et al., 1990, Kerzenmacher et al., 2006). However the temperature trend in the 
LS obtained is significant for both cases with and without post-Pinatubo. The temperature trends obtained show a significant cooling of the LS and a non-significant cooling of the UT over Reunion. As a result, we observed a cooling trend $(-0.36 \pm 0.48 \mathrm{~K}$ per decade) at CPT, while LRT exhibited a warming trend $(+0.12 \pm 0.39 \mathrm{~K}$ per decade).

The results obtained for temperature trends confirm the possibility that trend analyses over Reunion may be biased if post-Pinatubo data is not removed or adjusted for volcanic influence. Indeed, we note a difference in temperature trend estimate, whether post-Pinatubo data is taken into account or not: in the range of $0.32-0.41 \mathrm{~K}$ per decade. Furthermore, the analysis of temperature trends with and without IOD at CPT and LS suggests that IOD forcing contributes to increasing cooling by about $0.16 \pm 0.05 \mathrm{~K}$ per decade in the LS.

Finally, this multi-parameter regression analysis has shown that sea surface forcing due to the underlying Indian Ocean may influence the variation of temperature at CPT and LS layers. This result is found to correspond to the fact that cooling of the tropical LS is a dynamic result of tropospheric convection, which in turn partially depends upon SST anomalies. As a conclusion, from this study, we can suggest that the SST changes can be consider, in addition to effects due to ozone and carbon dioxide changes, to fully explain the observed temperature in the LS.

Acknowledgements. The LACy (Laboratoire de l'Atmosphère et des Cyclones) is supported by INSU (Institut National des Sciences de l'Univers), a CNRS institute, and by the Regional Council of Reunion (Conseil Régional de La Réunion). The present work is conjointly part of the Regional COMPTRAST programme and the ROZA project on the FRROI (Fédértion de Recherche Réunion-Océan Indien) programme of Reunion Island University. The co-authors are grateful to the LACy/OPAR radiosounding team (especially to Françoise POSNY and Jean-Marc METZGER) for their constant cooperation in radiosonde launching and data processing. The radiosonde data used in this paper is produced by the Observatory of Atmospheric Physics of Reunion Island (OPAR, http//:opar.univ-reunion.fr), within the framework of the NDACC and SHADOZ networks. We thank Anna Asperti for languages correction in this manuscript. The authors thank the editor T. J. Dunkerton and anonymous reviewers for very helpful reviews and relevant suggestions

Edited by: T. J. Dunkerton

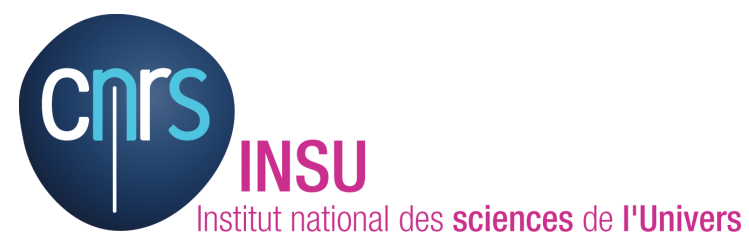

The publication of this article is financed by CNRS-INSU.

\section{References}

Angell, J. K.: Variations and trends in tropospheric and stratospheric global temperatures, 1958-87, J. Climate, 1(12), 12961313, 1988.

Baray, J.-L., Ancellet, G., Taupin, G., Bessafi, M., Baldy, S., and Keckhut, P.: Subtropical tropopause break as a possible stratospheric source of ozone in the tropical troposphere, J. Atmos. Sol.-Terr. Phys., 60, 27-36, 1998.

Behera, K. S. and Yamagata, T: Influence of the Indian Ocean Dipole on the Southern Oscillation, J. Meteorol. Soc. Jpn., 81(1), 169-177, 2002.

Bencherif, H., Portafaix, T., Baray, J. L., Morel, B., Baldy, S., Leveau, J., Moorgawa, A., Michaelis, M. M., Hauchecorne, A., Keckhut, P., and Diab, R.: LIDAR observations of lower stratosphericaerosols over South Africa linked to large scale transport across the southern subtropical barrier, J. Atmos. Sol.-Terr. Phys., 65, 707-715, 2003.

Bencherif, H., Diab, R., Portafaix, T., Morel, B., Keckhut, P., and Moorgawa, A.: Temperature climatology and trend estimates in the UTLS region as observed over a southern subtropical site, Durban, South Africa, Atmos. Chem. Phys., 6, 5121-5128, 2006, http://www.atmos-chem-phys.net/6/5121/2006/.

Clain, G., Baray, J.-L., Delmas, R., Diab, R., Leclair de Bellevue, J., Keckhut, P., Posny, F., Metzger, J. M., and Cammas, J. P.: Tropospheric ozone climatology at two southern Hemisphere tropical/subtropical site, (Reunion Island and Irene, South Africa) from ozone sondes, LIDAR, and in situ aircraft measurements, Atmos. Chem. Phys., 9, 1723-1734, 2009, http://www.atmos-chem-phys.net/9/1723/2009/.

Finger, F. G., Nagatani, R. M., Gelman, M. E., Long, C. S., and Miller, A. J: Consistency between variations of ozone and temperature in the stratosphere, Geophys. Res. Lett., 22, 3477-3480, 1995.

Gaffen, D. J: Historical changes in radiosonde instruments and practices, WMO/TD-No: 541, Instruments and Observing Methods Report 50, World Meteorological Organisation, 123 pp., 1993.

Gaffen, D.J: A digitized metadata set of global upper-air station histories, NOAA Tech. Memo. ERL-ARL 211, Silver Spring, MD, 38 pp., 1996.

Guirlet M., Keckhut, P., Godin, S., and Megie, G.: Description of the long-term ozone data series obtained from different instrumental techniques at a single location: the Observatoire de Haute-Provence $\left(43.9^{\circ} \mathrm{N}, 5.7^{\circ} \mathrm{E}\right)$, Ann. Geophys., 18, 13251339, doi:10.5194/angeo-18-1325-2000, 2000.

Hauchecorne, A., Chanin, M. L., and Keckhut, P.: Climatology and trends of the middle atmospheric temperature $(33-37 \mathrm{~km})$ as seen by Rayleigh lidar over the south of France, J. Geophys. Res., 96, 15297-15309, 1991.

Holton, J. R., Haynes, P. H., McIntyre, M. E., Douglass, A. R., Rood, R. B., and Pfister, L.: Stratosphere-troposphere exchange, Rev. Geophys, 33, 403-439, 1995.

Izumo, T., Valariad, J., Lengaigne, M., Boyer Montegut, C., Behera, K., Luo, J.-J., Cravatte, S., Masson, S., and Yamagata, T: Influence of the state of the Indian Ocean Dipole on the following year's El Niño, Nat. Geosci., 168-172, doi:10.1038/NGEO 760, 2010.

Keckhut, P., Hauchecorne, A., and Chanin, M. L.: Midlatitude longterm variability of the middle atmosphere: Trends and cyclic and episodic changes, J. Geophys. Res, 100(D9), 18887-18897, 
1995.

Kerzenmacher, T. E., Keckhut, P., Hauchecorne, A., and Chanin, M.-L: Methodological uncertainties in multi-regression analyses of middle-atmospheric data series, J. Environ. Monit, 8, 682690, 2006

Langematz, U., Kunze, K., Krüger, K. M., Labitze, K., and Roff, G. L: Thermal and dynamical changes of stratosphere since 1979 and their link to ozone and CO2 changes, J. Geophys. Res, 108(D1), 4027, doi:10.1029/2002JD002069, 2003.

Logan, J. A: Trends in vertical distribution of ozone: An analysis of ozonesonde data, J. Geosphys. Res., 99(D12), 25553-25586, 1994

Li, T., Leblanc, T., and McDermid, I. S.: Interannual variations of middle atmospheric temperature as measured by the JPL lidar at Mauna Loa Observatory, Hawaii $\left(19.5^{\circ} \mathrm{N}, 155.6^{\circ} \mathrm{W}\right)$, J. Geophys. Res., 113, D14109, doi:10.1029/2007JD009764, 2008.

McCormick, P., Thomason, L. W., and Trepte, C. R.: Atmospheric effects of the Mt Pinatubo eruption, Nature, 373, 399-404, 1995.

Morioka, K., Tomoki, T. and Yamagata, T: Climate variability in the southern Indian Ocean as revealed by self-organizing maps, Clim. Dynam., doi:10.1007/s00382-010-0843-x, 2010.

Mote, P. W., Rosenlof, K. H., McIntyre, M. E., Carr, E. W., Gille, J. C., Holton, J. R., Kinnersley, J. S., Pumphrey, H. C., Russell III, J. M., and Waters, J. W.: An atmospheric tape recorder: the imprint of tropical tropopause temperatures on stratospheric water vapor, J. Geophys. Res., 101, 3989-4006, 1996.

Naujokat, B.: An update of the observed quasi-biennale oscillation of the stratospheric wind over the tropic, J. Atmos. Sci., 43, 1873-1877, 1986

Oort, A. H. and Liu, H.: Upper-air temperature trends over the globe, 1958-1989, J. Clim., 6, 292-307, 1993.

Pan, L. L, Randel, W. J., Gary, B. L., Mahoney, M. J.,, and Hinsta, E. J: Definitions and sharpness of the extratopical tropopause: A trace gas perspective, J. Geophys. Res., 109, D23103, doi.10.1029/2004JD004982, 2004.

Parker, D. E.: On the detection of temperature changes induced by increasing atmospheric carbon dioxide, Q. J. Roy. Meteor. Soc., 111, 587-601, 1985.

Parker, D. E. and Cox, D. I: Towards a consistent global climatological rawinsonde data-base, Int. J. Climatol., 15, 473-496, 1995.

Parker, D. E., Gordan, M., Cullum, D. P. N., Sexton, D. M. H., Folland, C. K., and Rayner, N.: A new global gridded radiosonde temperature database and recent temperature trends, Geophys. Res. Lett., 24, 1499-1502, 1997.

Pastel, M., Goutail, F., Pazmiño, A., Pommereau, J. P., and Held, G.: Proceedings of Reunion Island International symposium, 143-146, 2007.

Pitari, G., Palermi, S. and Visconiti, G : Ozone response to a CO2 doubling: Results from a stratospheric circulation model with heterogeneous chemistry, J. Geophys. Res., 97(D5), 59535962, 1992.

Politowitcz, P. A. and Hitchman, M. H : Exploring the effect of forcing quasi-biennal oscillations in a two model, J. Geophys. Res., 102, 16481-16497, 1997.

Posny, F., Metzger, J. M., and Baray, J. L.: A successful change at la Reunion Island station $\left(21^{\circ} \mathrm{S}, 55.5^{\circ} \mathrm{E}\right)$, SHADOZ Newsletter, No. 11, 2010.

Ramaswamy, V., Chanin, M.-L., Angell, J., Barnett, J., Gaffen, D., Gelman, M., Keckhut, P., Koshelkov, Y., Labitzke, K., Lin, J.-J.
R., O’Neill, A., Nash, J., Randel, W., Rood, R., Shine, K., Shiotani, M., and Swinbank, R.: Stratospheric temperature trends: observations and model simulations, Rev. Geophys., 39(1), 71122, 2001.

Randel, W. J. and Cobb, J. B.: Coherent variations of monthly mean column ozone and lower stratospheric temperature, J. Geophys. Res., 99(D3), 5433-5447, 1994.

Randel, W. J., Wu, F., and Gaffen, D. J : Interannual variability of the tropical tropopause derived from radiosonde data and NCEP reanalyses, J. Geophys. Res., 105, 15509-15523, 2000.

Randel, W. J., F. Wu, Oltmans, S. J., Rosenlof, K. H., and Nedoluha, G. E: Interannual changes of stratospheric Water vapour and correlations with tropical tropopause temperature, J. Atmos. Sci., 61, 2133-2148, 2004.

Randel, W. J, Wu, F., Vomel, H., Nedoluha, G. E., and Forster, P : Decreases in stratospheric water vapour after 2001: Links to changes in the tropical tropopause and the BrewerDobson circulation, J. Geophys. Res., 111(D12), D12312, doi:10.1029/2005JD006744, 2006.

Randel, W. J, Shine, K. S, Austin, J., Barnett, J., Claud, C., Gillett, N. P., Keckhut, P., Langematz, U., Lin, R., Long, C., Mears, C., Miller, A., Nash, J., Seidel, D. J, Thompson, D. W. J, Wu, F., Yoden, S.: An update of observed stratospheric temperature trends, J. Geosphys. Res., 114, D02107, doi:10.1029/2008JD010421, 2009.

Reid, G. C. and Gage, K. S.: On the annual variation in height of the tropical tropopause, J. Atmos. Sci., 38, 1928-1938, 1981.

Reid, G. C. and Gage, K. S: Inter-annual Variations in the height of the tropical tropopause, J. Geophys. Res., 90(D3), 5629-5635, 1985.

Rosenlof, K. H., Kley, D., Russell III, J. M, Chiou, E. W, Johnson, D. G, Kelly, K. K., Michelsen, H. A., Nedohula, G. E., Remsberg, E. E., Toon, G. C., and McCormick, M. P.: Stratospheric water vapour increases over the past half century, Geosphys. Res. Lett., 28, 1195-1199, 2001.

Rosenlof, K. H. and Reid, G. C.: Trends in the temperature and water vapor content of the tropical lower stratosphere: Sea surface connection, J. Geophys. Res., 113, D06107, doi:10.1029/2007JD009109, 2008.

Saji, N. H., Goswami, B. N., Vinayachandran, P. N., and Yamagata, T.: A dipole mode in the tropical Indian Ocean, Nature, 401, 360-363, 1999.

Seidel, D. J., Ross, R. J., and Angell, J. K.: Climatological characteristics of the tropical tropopause as revealed by radiosonde, $\mathrm{J}$. Geophys. Res., 106, 7857-7878, 2001.

Sivakumar, V., Baray, J. L., Baldy, S., and Bencherif, H.: Tropopause characteristics over a southern subtropical site, Reunion Island $\left(21^{\circ} \mathrm{S}, 55^{\circ} \mathrm{E}\right)$ : Using radiosonde-ozonesonde data, J. Geophys. Res., doi:10.1029/2005JD006430, 2006.

Sivakumar, V, Portafaix, T., Bencherif, H., Godin-Beekmann, S. and Baldy, S: Stratospheric ozone climatology and variability over a southern subtropical site: Reunion Island $\left(21^{\circ} \mathrm{S} ; 55^{\circ} \mathrm{E}\right)$, Ann. Geophys., 25, 2321-2334, doi:10.5194/angeo-25-23212007, 2007.

Sorensen, J. H. and Nielsen, N. W.: Intrusion of stratospheric ozone to the free troposphere through tropopause folds-A case study, Phys. Chem. Earth (B), 26, 801-806, 2001.

Tiao, G. C., Daming, X., Pedrick, J. H., Xiaodong, Z., and Reinsel, G. C.: Effect of autocorrelation and temporal schemes on 
estimates of trend and spatial correlation, J. Geophys. Res., 95, 20507-20517, 1990.

Thompson, A. M., Witte, J. C., McPeters, R. D., Oltmans, S. J., Schmidlin, F. J., Logan, J. A., Fujiwara, M., Kirchhoff, V. W. J. H., Posny, F., Coetzee, G. J. R., Hoegger, B., Kawakami, S., Ogawa, T., Johnson, B. J., Vömel, H., and Labow, G : Southern Hemisphere Additional Ozonesondes (SHADOZ) 1998-2000 tropical ozone climatology: 1.Comparison with Total Ozone Mapping Spectrometer (TOMS)and ground-based measurements, J. Geophys. Res., 108(D2), 8238, doi:10.1029/2001JD000967, 2003

Thompson, A. M., Witte, J. C., Oltmans, S. J., Schmidlin, F. J., Logan, J. A., Fujiwara, M., Kirchhoff, V. W. J. H., Posny, F., Coetzee, G. J. R., Hoegger, B., Kawakami, S., Ogawa, T., Fortuin, J. P. F., and Kelder, H. M.: South Hemisphere Additional Ozonesondes (SHADOZ) 1998-2000 tropical ozone climatology: 2.tropospheric variability and the zonal wave-one, J. Geophys. Res, 108(D2), 8241, doi:10.1029/2002JD002241, 2003.

Thompson, A, Witte, J. C., Herman, G. J., Oltmans, S. J., Johnson, B. J., Volker W. J., Kirchoff, V. W. J. H., and Schmidlin, F. J.: Soutern Hemisphere Additionnal Ozonesonde (SHADOZ) 19982004 tropicale ozone climatology: 3. Instrumentation, station to station variability, and evaluation with simulated flight profiles, J. Geophys. Res., 112(D3), D03304,, doi:10.1029/2005JD007042, 2007.
Weatherhead, E. C., Reinsel, G. C., Tiao, G. C., Meng, X., Choi, D., Cheang, W., Keller, T., DeLuis, J., Wuebbles, D. J., Kerr, J. B, Miller, A. J, Oltmans, S. J., and Frederick, J. E.: Factor affecting the detection of trends: Statistical considerations and application to environmental data, J.Geophys.Res., 103(D14), 17149-17161, 1998.

WMO: A three dimensional science: Second session of the commission for aerology, WMO bull, IV, (4), 134-138, 1957.

WMO: Scientific assessment of ozone depletion: 1994, Global Ozone Res. Monit. Proj., Rep. 37, 1995.

WMO: Scientific assessment of ozone depletion: 2006, Global Ozone Res. Monit. Proj., Rep. 50, 2007.

Yamagata, T., Behera, S. K., Luo, J. J, Masson, S., Jury, M. R., and Rao, S. A: Coupled Ocean-Atmosphere Variability in the Tropical Indian Ocean., American Geophysical Union Book Ocean-Atmosphere Interaction and Climate Variability, Washington DC, USA, 189-212, 2004. 